\title{
Collective Responsibility and Group-Control
}

András Szigeti

\begin{abstract}
Collectives are more or less structured groups of human beings. Responsibilitycollectivism is the view that the moral responsibility of at least some such collectives is something over and above the combined moral responsibility of individual group members. This paper focuses on one of the key conditions of responsibility: the requirement of control. It is plausible that this requirement also applies to collective agents and so collective responsibility presupposes group-control. Responsibilitycollectivists have often tried to unpack the idea of group-control as non-causal control. I argue that non-causal control is not an admissible basis for attributing responsibility. Only causal group-control is. This is because non-causal group control does not provide the right kind of information regarding the ancestry of a certain outcome. In the second half of the paper, I discuss the difficulties which arise for responsibility-collectivism if one understands group-control as causal group-control. One of these difficulties is whether causal group-control is consistent with ontological individualism. The second concerns the relationship of group-control and individual control. I argue that the first difficulty is manageable, but only at the price of having to accept a solution to the second difficulty which runs counter to the original aim of the responsibility-collectivist of characterizing irreducible collective responsibility as compatible with individual responsibility. Worse still, responsibility-collectivists may have to choose sides in other areas of social ontology as well. This further raises the price of this position.
\end{abstract}




\section{Introduction}

Collectives are groups of human beings ranging from formal organizations (e.g., corporations, intergovernmental bodies) to associations of various kinds (e.g., clubs, teams, armies) and random assemblages of people (e.g., victims of an environmental disaster) (Held 1970; French 1979; 1984; May \& Hoffman 1991). Responsibilitycollectivism is the view that the moral responsibility of at least some such collectives is something over and above the combined moral responsibility of individual group members. ${ }^{1}$ I will refer in the following to such supposedly irreducible collective responsibility as robust collective responsibility (or sometimes the responsibility of the group qua group).

One consideration typically invoked in support of collectivism about responsibility is that without attributing responsibility to collectives qua collectives there will be a "deficit in the accounting books" (Pettit 2007a, 194; see also French 1979, 207; Kutz 2000, 113; Copp 2006, 216, etc.). That is to say, nobody will be called to task for many kinds of harms ( or praised for the benefits) the source of which appears to be the existence of collectives. This seems worrying in view of the impact corporations, governments and international organizations can have on our lives.

The said deficit can arise, it is argued, because the responsibility of the group qua group does not necessarily reduce to the aggregate responsibility of individual members of the group (and also does not translate into the aggregate plus the individual responsibility of non-members). In the most dramatic cases, it is possible that there is no responsibility to be allocated at the individual level at all, and yet the group is morally responsible as a group. In general, responsibility-collectivists think that the following can be true: You have allocated all the moral responsibility there is to be allocated at the individual level, and still you have not allocated all the responsibility there is to be allocated. If you want to allocate all the responsibility there is to be allocated, you have to ascribe responsibility to the group as a group as well. Hence the need for the concept of robust collective responsibility.

Strictly speaking the responsibility-collectivist makes two claims. First, that in certain collective contexts "responsibility-voids" (to borrow an expression from Braham \& van Hees 2011) can arise. This can happen, among others, due to formal characteristics of collective decision-making processes, or because responsibilityundermining excuses apply to the participating individual agents (Copp 2006), or because the moral significance of individual contributions does not "add up" to the wrongness of the collective outcome, e.g., when the relevant effect is massively

\footnotetext{
1 The version of responsibility-collectivism I will focus on holds that it is the same kind of moral responsibility we attribute to collectives as to individuals. That is, roughly, retrospective desert-based responsibility implying blameworthiness and praiseworthiness and justifying certain normative responses such as punishment and Strawsonian reactive attitudes such as resentment and guilt. Pettit (2007a) and Shockley (2007) explicitly accept this condition.
} 
overdetermined and/or the individual contribution is very small (Kutz 2000, Lawson 2012). The second claim is that at least some of these voids should be filled by allocating responsibility directly to the collective. ${ }^{2}$

In the present context, ought certainly implies can, so if responsibilitycollectivists are to make good on their claim that we should sometimes ascribe responsibility to the group qua group, then they have to show that we can ascribe responsibility to the group qua group. The task, in short, is to show that groups can be proper addressees of responsibility-ascriptions, that some groups at least are "fit to be held responsible" (Pettit 2007a). Since there is a good case to be made that moral responsibility presupposes agency, this task will involve, among others, showing that the collectives can be agents.

But agency is not sufficient for moral responsibility - further conditions have to be met for an agent to qualify as an addressee of (moral) responsibility-ascriptions. In this paper, I will focus on one of the key conditions said to be required for collective responsibility. This is the requirement of control. Clearly, any agent will have to be able to have some control over whatever ${ }^{3}$ she is found responsible for. So collective agents too have to be able to exercise some control over whatever it is they are found collectively responsible for. ${ }^{4}$

This is not disputed by parties to the debate (Section 2). However, for reasons to be explained below (Section 3), responsibility-collectivists have often tried to unpack the idea of group-control as non-causal control (see esp. Pettit 2007a, Shockley 2007). I will argue that non-causal control is not an admissible basis for attributing responsibility (Section 4). My suggestion is to accept that moral responsibility requires causal control. If we therefore take the idea seriously suggested by the responsibility-collectivist that collectives can be morally responsible agents in the same sense as individual agents, which is the responsibility-collectivist's avowed aim, then the relevant collectives are to meet the causal condition as well. Non-causal group-control cannot justify ascribing responsibility to the collective. Only causal group-control would.

In the second half of the paper (Sections 5-8), I will also discuss the difficulties that arise for responsibility-collectivism if one understood group-control as causal group-control (Section 5). One of these difficulties is whether causal group-

\footnotetext{
2 One feasible strategy available to the responsibility-individualist is to accept the first claim, but reject the second. Perhaps we just have to resign ourselves to the fact that collectively brought about harms can also sometimes be of a kind for which nobody is responsible, comparable to harms inflicted by nature, even though they are in some sense "man-made" (see Szigeti 2014).

3 Responsibility for what, i.e., actions or outcomes of actions? When necessary to specify, I will focus on responsibility for outcomes for simplicity's sake. Elsewhere I will follow Pettit (2007a) who does not distinguish between responsibility for actions and responsibility for outcomes. The distinction may be relevant to the requirement of control insofar as the necessity of causal control is widely held for outcomeresponsibility (actions causing outcomes). By contrast, some libertarians (simple indeterminists) do not accept that agents need to cause the actions for which they are responsible (see Goetz 1988).

${ }^{4}$ Naturally, one can also argue against the collectivist position using the dependence of responsibility on agency as one's point of departure. If no groups of human beings can be agents and moral responsibility presupposes agency, then individualism about responsibility would follow (for such responsibilityindividualist arguments, see Miller \& Mäkelä 2005; Haji 2006; McKenna 2006). Shockley (2007) denies that collective moral responsibility presupposes collective agency, but accepts the control-requirement.
} 
control is consistent with ontological individualism. The second concerns the relationship of group-control and individual control. I argue that the first difficulty is manageable (Section 6). However, it is only manageable at the price of having to accept a solution to the second difficulty that runs counter to the original aim of the responsibility-collectivist. This aim was to characterize irreducible collective responsibility as compatible with individual responsibility (Section 7). Worse still, responsibility-collectivists may have to choose sides in other areas of social ontology. This further raises the price of this position (Section 8).

\section{Responsibility-collectivism and group-control}

There is an obvious worry about responsibility-collectivism. Collectivists ${ }^{5}$ would not want to deny that individual human beings act when Tim, Dick or Harry signs the contract, fires the gun, votes for awarding tenure, etc., and not IBM, the execution squad, or the committee. Thus Pettit says, for example: "Whatever a group does is done by individual members on behalf of the group and is done intentionally by those individuals." (Pettit 2007a, 191). Formal organizations are typically seen as the strongest candidates among the different types of collectives to qualify as full-blown collective agents (French 1979). Yet everybody seems to agree that even in the case of formal organizations: "whatever the organization does is done by its members in its name" (Ylikoski 2012, 32).

Nevertheless, the collectivist suggests that it is sometimes appropriate to describe some individual actions as actions controlled by the group. This would also explain why we should hold the collective responsible in the relevant cases. It is plausible to say that the collective is to incur responsibility qua collective for whatever it controls qua collective (provided the collective also meets other criteria of "responsibility-fitness").

When saying that an agent is in control of $X$, I mean that it is up to the agent whether $X$ will obtain or take place. This is in accordance with how this concept is standardly used in the literature (see O'Connor 1995; Fischer \& Ravizza 1998). If an agent is in control of her action, then it is up to her whether she will undertake that particular action. If an agent is in control of an outcome, then it is up to her whether that outcome will take place. We can say that at the very minimum when an agent is in control the pathway to future states of the world lead through her agency. ${ }^{6}$ The world unfolds in the way it does because of her agency. ${ }^{7}$

Collectivists do not wish to deny either that even when the individual action is controlled by the group the individual can act freely and voluntarily. The kind of

\footnotetext{
5 In this chapter, the unadorned term "collectivist" or "collectivism" is always to be read as short for responsibility-collectivism or responsibility-collectivist as I defined the position in the first paragraph.

6 I say "at the very minimum" in order to accommodate the semi-compatibilist argument that control as defined above is all that is required in terms of control for the agent to be morally responsible, whereas regulative control associated with the ability to do otherwise is not (see Fischer \& Ravizza 1998). Note that both kinds of control are described by semi-compatibilists as causal.

7 I will define causal control in Section 5 below.
} 
group-control the collectivist is after does not exclude that the individual who is controlled by the group is capable of resisting group-control. For example, she may refuse to implement the group's policies or decisions and she is individually responsible for that choice. But if this is true, then the individual retains some control over her actions even when those actions are controlled by the group (see, for example, Pettit 1996; 2007a).

It is easy to see why the responsibility-collectivist would want to insist on this point despite the difficulties it gives rise to. Intuitively, many of the paradigmatic cases of robust collective responsibility discussed by the collectivist - e.g., employees acting in the name of their companies or organizations - do not seem to involve diminished individual responsibility (see Kutz 2000). That is, in many of these cases, the individual agents appear to be fully fit to be held responsible themselves, and that is how their individual actions will be assessed morally. In general, the aim of the responsibility-collectivist is not to fill one "gap in the accounting books" by creating another. It is hoped that responsibility-allocation will not turn out to be a zero-sum game as regards the distribution between the individual and collective levels. Rather, the idea is to show that even when all individual responsibility has been allocated, it is possible that there will still be something the collective can be morally responsible for as a collective. Moreover, even in those special cases when there is no individual responsibility to be allocated, responsibility is not allocated to the collective faute de mieux, i.e., only because no individual is responsible.

It follows that the notion of group-control crucially hinges on the question of how group-control is related to individual control. The collectivist needs to explain how the group can control certain actions of its individual members whereby such group-control (i) does not undermine the individual's control over her actions, but (ii) nevertheless is such that the group also becomes responsible as a group for those actions. The collectivist believes that some groups in fact control at least some of the actions of participating individuals in a sense that meets both conditions (i) and (ii). The suggested collectivist solution I will consider here first (Sections 3-4) purports to show that the group can control actions of its members non-causally by arranging that certain individuals perform certain actions and that they perform those actions in certain ways (Pettit 2007a, 191; Shockley 2007). Such "programming" is not causally efficacious itself. Only individual actions are causally efficacious. ${ }^{8}$ Nevertheless, the program is somehow supposed to ensure that the individual actions will in fact produce the effects foreseen by the given collective. ${ }^{9}$

For example, many groups may be ascribed a constitutionally-enshrined or tacitly agreed-upon purpose or policy (e.g., help the poor, conquer the Japanese market, win the Olympics). Other groups may not have long-term policies, but can still be characterized as being committed to a collective judgment on some normative or factual issue. These collective purposes, policies or judgments can be seen as the

\footnotetext{
8 More precisely, the physical realizations (which are property-instantiations) of the individual actions. I ignore that complication here.

9 In addition, the responsibility-collectivist also needs to show that group-control is not just control by some other individual or aggregate of individuals. This task involves, among others, showing that when the group is in control the relevant individual actions implement some autonomous group attitude held by the group qua group. I will not discuss the difficulties associated with this issue in this paper (but see Szigeti (2014) and footnote 18 below).
} 
"program" which the relevant individual actions implement. Emphatically, the influence of the program on the individual actions is not supposed to be causal ${ }^{10}$ and should be consistent with individual control. Nevertheless, when some individual does implement the program, then the group's impact on the individual action can be decisive enough to make the group responsible as a group as well. Or so the collectivist argues.

Two closely related questions arise with regard to this idea. First, in what sense does the "program" control the relevant individual actions without causing them? And second, how can the "program" be the basis for attributing responsibility to the group qua group if it does not cause the relevant individual actions? I reconstruct the collectivist answer to these questions in the next section before turning to my objections.

\section{Non-causal group-control}

The idea of non-causal group-control is an application of a general theory about higher-order explanations in the special sciences, folk psychology and elsewhere (Jackson \& Pettit 1990). That theory offers a novel, non-reductionist solution to the problem of the causal relevance of higher-order properties in such explanations. ${ }^{11}$ The suggested solution is that higher-order properties, while not being causally efficacious themselves, constitute an indispensable part of causal explanations. These higherorder properties are therefore causally relevant.

Some such theory of higher-order properties is required in order to account for the problem of how to square with one another the following assumptions, all of which appear to be prima facie plausible: (i) only lower-level (physical) properties are causally efficacious, (ii) higher-level properties (such as those studied by the special sciences, e.g., psychological properties) are not reducible to lower-level properties, but nevertheless (iii) supervene on physical properties, and (iv) there are significant explanatory generalizations directly linking higher-level properties to one another (e.g., about causal relations between psychological states), and (v): if a lower-level property is causally sufficient for some effect, then typically (that is, barring cases of overdetermination) no property supervening on that lower-level property can be causally efficacious in bringing about that effect (the so-called exclusion principle). The question is: if (v) is accepted, then how can we save (iv), i.e., establish the nonredundancy of generalizations in terms of higher-level properties, and hence the

\footnotetext{
10 Having said that, it should be noted that, despite their insistence that "programming" is a strictly noncausal process, the language used by advocates of this theory is worryingly causal at times. They talk about the program or arrangement as "ensuring" or "making it probable" (Jackson \& Pettit 1990, 114) that basic, causally efficacious factors will bring about the pertaining effect (for the same causal language, see also Jackson \& Pettit 1992a; 1992b).

11 In the following, I will mostly talk about higher-order/lower-order properties, not events. It will be assumed that the problem and possible solutions would be about the same for higher-order/lower-order events as well.
} 
autonomy of the special sciences? The "programming-perspective" has been proposed to solve this problem. ${ }^{12}$

The explanatory indispensability of higher-order properties is said to be demonstrated by the fact that if we ignored them we would miss out on essential information regarding the causal process. The causally relevant piece of information is this: if the given causally efficacious factor had not caused the effect, another similar factor would have (Jackson \& Pettit 1992b). This counterfactual obtains because of the "programming". For example, the boiling of water in a closed container may be indispensable to explaining why the wall of the container cracks, even though the causally efficacious factor was in fact the collision of a given $\mathrm{H}_{2} \mathrm{O}$ molecule (or micro cluster of $\mathrm{H}_{2} \mathrm{O}$ molecules) of a certain momentum with the glass. The macro property of boiling is causally inefficacious and supervenes on the basic, causally efficacious micro property. At the same time, that the water is at boiling temperature "programs for" the collision of one or the other molecule (or molecular cluster) with the wall of the container. So the boiling is causally relevant to the explanation of why the container cracks.

This general theory is also applied to group-control (see esp. Pettit 2007a; Shockley 2007; List \& Pettit 2011). According to the collectivist, a group can control actions of its members by non-causally "programming" for those actions. We have already provided a preliminary sketch of how this is supposed to happen in the previous section. Groups are committed to certain goals or policies or a collective judgment. These commitments constitute the "program". In addition, many groups also have a clear division of labour for the implementation of these commitments. As a result, the group will have structured or "programmed for" the actions of the participating individuals by making sure that if one participating individual fails to perform his role within the given division of labour, then some other member will step in. Again, the claim is not merely epistemic: the decisive counterfactual is said to obtain because of the "programming". Additional evidence offered in support of noncausal group-level control is that changing membership need not disrupt the functioning of the group. This is possible because the group will ensure in the "programming" sense that the new members will continue to promote the group functions. ${ }^{13}$

\section{Non-causal group-control and collective moral responsibility}

I will not discuss the general theory about the causal relevance of higher-order properties here. The point I would like to make is that even if that theory can justify distinguishing among different levels of explanation (Jackson \& Pettit 1992a), it does not help in grounding robust collective responsibility.

\footnotetext{
12 A possible alternative is to deny (i). See Woodward 2008, Menzies 2008, List \& Menzies 2010, Shapiro 2012. More on this alternative in Section 6.

13 Furthermore, the collectivist argues that there are good reasons why the group should exercise such control over its members. Group-control may be required to ensure both the diachronic and synchronic rationality of collective behaviour (List \& Pettit 2002; Pettit 2003; List 2006; Pettit 2007b; List \& Pettit 2011). Of course, collectivists also acknowledge that groups can also fail to perform their functions or can even fall apart completely.
} 
Since the "program" is itself causally inefficacious, it makes no direct contribution to any given outcome (pace Shockley 2007). This is granted by advocates of the "programming account". The boiling does not break the glass - some molecule does. The corporate does not sign the contract - some manager does. The reason why the "program" is said to be causally relevant is that it provides information about how the causal history leading up to that event could have gone. For example, given that the water was boiling, if not this molecule or molecular cluster, then another would have shattered the glass. But this counterfactual information about possible alternative causal histories is irrelevant as regards the moral responsibility of the collective.

Consider the case of punishment and other sanctions based on statistical profiling: Given certain psychological-cum-sociological profiles, it can be highly likely that individuals of that profile will commit certain crimes. We can say that the profile "programs for" the committing of those crimes: if not this particular person of that profile will commit the crime, then the next one with the same profile very likely will. In fact, some argue that given the likelihood that individuals of a distinct profile will commit certain crimes, profiling in itself can constitute a sufficient justification for the application of certain sanctions including punishment. This is of course a highly contentious issue.

However, even if we were to accept this argument about profile-based sanctioning, note the following. It makes no sense to say that we should ascribe responsibility to the profile on account of its explanatory role, namely that it "programs for" the committing of the particular sort of crime. Crucially, this worry is conceptual, not moral. One cannot hold an abstract statistic morally responsible. That is not a question of moral justifiability, but a matter of avoiding a category mistake.

By the same token, one might perhaps argue that we should impose certain sanctions on members of a collective provided membership in the collective is demonstrably correlated with an increased likelihood of whatever morally or legally objectionable actions. And yet even if this (questionable) argument was to be accepted, it would not follow that we hold the collective robustly responsible in such cases. "Programming" is an abstract metric characterizing certain distributions or topologies. ${ }^{14}$ Consequently, it cannot be held morally responsible. Again, doing so would simply amount to a category mistake.

It may be replied here that there is a crucial difference between the profile in an example such as the one above and the "program". The "program" has been "written" by the collective, it may be said. Think of a corporate policy or some binding rule adopted by (say) a consensus or a majority vote. ${ }^{15}$ The program then could perhaps be interpreted as a set of instructions or guidelines given by the group to the individual agent who implements the program or some part of it. Collective

\footnotetext{
14 Note that collectivists themselves write that in the case of the cracking flask, for example, the higherorder property of boiling is an "abstract statistic" (Jackson \& Pettit 1992b, 117; the term used in the same context in Jackson \& Pettit 1990, 110 is "aggregate statistic").

15 Some responsibility-collectivists also emphasize the importance of other, less formal ways of adopting a "program" such as via a shared culture or common norms or goals or feelings of solidarity (May 1991; Shockley 2007).
} 
control of the relevant individual actions would be ensured through these instructions or guidelines.

This objection is misguided, however. First, as clear-headed collectivists themselves acknowledge "[j]ust as anything that the group does is done by members, any instructions that the group gives are given by one or more members" (Pettit 2007a, 189). So the attempted reply by the collectivist would only push the problem back one stage. The problem about collective control would now have to be posed about those intentional actions which amount to the giving of instructions to the implementing individual. ${ }^{16}$

Second, as regards the question of control it is actually irrelevant who put the "program" in place. The question is why the collective should be responsible as a collective when some individual implements that "program". Now, it may be true that if this individual decided not to implement the "program", then another individual would have. The problem is that the "programming account" fails to explain what role the collective qua collective plays in getting this or that particular individual to implement the program.

As noted, according to the collectivist "programming" by the collective should be compatible with individual control on the part of those who implement the program (Jackson \& Pettit 1992b, 130). However, an immediately striking difference to molecules in the boiling case is that in many cases the individual agent in a collective is free to refuse to carry out the program and voluntarily complies when she does. Being causally inefficacious, the "program" merely identifies what the required tasks are and ensures that each task will be carried out by some member of the collective: "maybe these or maybe those" (Pettit 2007a, 192). But if that is the case, then it is hard to see how the collective is supposed to control individual action qua collective. ${ }^{17}$

To conclude, given that the "program" itself is causally inefficacious, the "program" merely predicts but does not make it the case or "ensure" that some individual will implement the "program". Consequently, even if it makes sense to talk about there being a "program" in place in some collectives this does not make the collective responsible for any individual actions, not even if other conditions of collective responsibility could be met. ${ }^{18}$

\footnotetext{
16 In general, the collectivist is to avoid circularity. It cannot be argued that what distinguishes a collective profile as in the above example from genuine group-control is that group-control is exercised by the collective as an agent (pace Pettit 2007b). Collectivists themselves accept that for a collective to qualify as an agent it already has to possess group-control.

17 It is worth noting as well that the "program" does not even make a counterfactual contribution in the sense of making sure that a Frankfurtian back-up plan would be executed. It is not the case that should this individual fail to comply, the program would ensure that the program is nevertheless implemented by making someone else do it. So if individual agent $\mathrm{I}_{1}$ fails to perform her task and some other individual agent $I_{2}$ steps in and performs the action instead, then that will be once again $I_{2}$ 's choice given that program is causally inefficacious.

18 Including the condition, extensively discussed by responsibility-collectivists (see esp. List \& Pettit 2011), that the group has to be able to hold autonomous judgments which can come apart from judgments of individual members. I have argued elsewhere (Szigeti 2014) that it does not follow from the possibility of group judgments being autonomous in this sense that the group qua group is responsible for them. This because either some individual or nobody is responsible for these collective judgments. By contrast, my
} 


\section{Causal group-control?}

At this point, the obvious question is: why not save responsibility-collectivism by adopting a causal understanding of group-control? Recall the definition of control above (Section 2): when an agent is in control of $X$, say an outcome, it is up to the agent whether $X$ will obtain or take place. Causal control then means that the dependence of the outcome on the agent will be causal. The agent will influence what will happen by causally interacting with the world.

It is quite plausible that there is an intimate connection between causal control and moral responsibility. At least when it comes to individual action, there appears to be a near consensus that I am not morally responsible for an outcome unless I had causal control over that outcome (Fischer \& Ravizza 1998; Moore 2009). ${ }^{19}$ It is causal control which ensures that I am hooked up to the world so that I at least stand a chance of impacting on what happens out there (Gilbert 2002; Sartorio 2004 ${ }^{20}$ ). Lacking such control, the necessary link is severed. Thus, other things being equal, merely approving of $X$ or thinking that it is a good thing that $X$ happens will not make one responsible for $X$ if approval has no causal effect whatsoever. Allocating causal responsibility is of course a difficult matter because a number of agential contributions may be necessary for a given outcome. The point here is only that if an agent is not in a position to make any causal contribution to bringing about $X$, then that agent will not be morally responsible for $X$. But non-causal control appears to make collective agents causally impotent in this way.

So the question is: Since the requirement of causal control is so plausible, and if my objections are on the right track, "programming" cannot be sufficient for collective moral responsibility even if all other conditions of "responsibility-fitness" are met, why not unpack the concept of group-control as causal control? In the following two sections, I want to point to two problems which may be seen as standing in the way of this strategy. The first of these seems manageable. But solving that problem comes at the price of having to accept a response to the second problem which I believe will be found unappealing by many responsibility-collectivists.

point here is that even if group judgments can be autonomous in this sense, this does not mean that the group controls individual actions when individuals implement those judgments.

19 As noted earlier, simple indeterminist libertarians question the requirement of causal control for the agent-action as opposed to the action-outcome relationship. However, it seems that they too would accept the requirement of causal control for the action-outcome relationship.

20 Admittedly, Sartorio denies that moral responsibility entails causal responsibility. I am not sure whether she would also deny the requirement of causal control as defined above. 


\section{Causal group-control and ontological individualism}

The first problem is that if group-control is cashed out as causal control, then this entails attributing causal efficacy to collectives (or causal powers to use a slightly different idiom). That is, groups qua groups will have to be treated as causally efficacious factors in causal explanations. The question is whether doing so would saddle the responsibility-collectivist with unwelcome ontological commitments such as ontological holism. Almost everyone today, and certainly responsibilitycollectivists discussed in this paper, embrace ontological individualism (Zahle 2007; Epstein 2009). This is the view that group-level properties supervene on properties of individuals. Fix properties at the individual level and you will have fixed all the group-level properties as well (List \& Pettit 2011, 89).

The worry then is that understanding some collectives as causally efficacious factors may not be consistent with ontological individualism understood in this way. This worry is based on the exclusion principle mentioned earlier. It follows from this principle that if properties of collectives are indeed supervenient on properties about individuals, then those properties cannot be causally efficacious. The "programming account" has been suggested precisely to avoid both of two seemingly unattractive positions: the Scylla of denying the exclusion principle and the Charybdis of denying the relevance of higher-order properties to causal explanations. As we have seen, the suggested solution consisted in the claim that higher-level properties, i.e., the "program", can be causally relevant without being causally efficacious. If so, then collectives too can be causally relevant without being causally efficacious. We have also seen, however, that denying the causal efficacy of collectives creates a serious problem for responsibility-collectivists because if collectives are not causal efficacious it is hard to see how they can control outcomes.

This problem generalizes. ${ }^{21}$ If higher-level properties are not causally efficacious, then they will be causally inert, that is, epiphenomenal. But if higherlevel properties are epiphenomenal, then it is hard to see how they can nevertheless be relevant to causation (see Crane 2008, 189). Acknowledging this problem, many bite the bullet and argue that we should attribute causal efficacy to higher-level properties. Such solutions are based on replacing what many see as a "tendentious conception of causation" (Shapiro 2012) underlying the original formulation of the exclusion principle.

It is suggested that if we adopt a counterfactual account of causation, there is no principled obstacle to attributing causal efficacy to higher-level properties (Yablo 1992; Woodward 2003; 2007; 2008; List \& Menzies 2009; 2010, etc.). ${ }^{22}$ Setting aside a number of complications and refinements discussed since the classic formulation of the account by David Lewis (1973), the gist of the counterfactual account is that for

\footnotetext{
21 Which is not surprising since, as noted above, the "programming account" is a general proposal for distinguishing the causal relevance of higher-level properties from the causal efficacy of lower-level ones.

22 Note that libertarian agent causationists have argued that attributing causal efficacy to certain emergent properties does not even require repudiating the conception of causation as generation or production (see esp. O'Connor 1994; 1995).
} 
two distinct events ${ }^{23} c$ and $e, e$ causally depends on $c$ iff: (i) if $c$ were to occur $e$ would occur $(C \square \rightarrow E)^{24}$ and (ii) if $c$ were not to occur $e$ would not occur $(-C \square-E$ ). It will be especially important to keep in mind for what follows that causal dependence is formulated in terms of the truth of both the negative and a positive counterfactual (i) and (ii) (see Lewis 1973, 563). ${ }^{25}$

This general solution can be used to attempt to capture the causal role of collectives as well. It is clear that many relevant counterfactuals involving collectives will come out true. Consider claims such as "had the mob not stormed the Bastille, it would not have fallen" or "if the National Bank raised interest rates, inflation would fall". What is more, there appears to be a robust counterfactual dependence between properties of collectives and corresponding effects in that both negative and positive counterfactuals of the type (i) and (ii) above appear to hold. If so, then we could regard collectives as causally efficacious using the counterfactual account (see esp. List \& Menzies 2009; 2010).

At the same time, it is not disputed by advocates of higher-level causation that causally efficacious higher-level properties remain supervenient on lower-level properties. Thus in the case of collectives too, when the properties of collectives are deemed to be causally efficacious these collective properties supervene on the properties of individuals. Take the examples above. It is not questioned that fixing the properties of individual members of the mob will also fix the properties of the mob itself, and fixing the properties of individuals constituting the National Bank will fix the properties of the National Bank. Unless there is a difference in individual properties, there will be no difference in collective properties.

So we have a well-developed approach which, by making use of the counterfactual account of causation, promises to make ontological individualism and higher-level property causation compatible. What remains to be seen, finally, is whether responsibility-collectivism fits into this picture. As we have seen, the prospects of responsibility-collectivism depend not just on whether collectives can be causally efficacious, but also on the relationship between the respective causal roles or powers of collective and individual properties. This brings us to the second problem for the responsibility-collectivist. I will argue in the next section that this problem of "too many causes" (Woodward 2008, 250) might well prove intractable for the responsibility-collectivist.

\section{Causal group-control and the problem of exclusion}

Recall that the "programming account" has been proposed not just as a general solution to the exclusion problem, but also to solve an issue specific to the debate about collective responsibility. This specific issue was to find a notion of group-

\footnotetext{
23 Note that in terms of this definition the causal relata for Lewis are events, whereas in the rest of the paper I talk about properties, or better property-instantiations, as causal relata. I believe we can ignore this difference for the purposes of this paper.

24 Whereby $C$ and $E$ are propositions referring to the occurrence of the corresponding events or the instantiations of properties.

25 Whereby the truth of counterfactuals is interpreted, as is standard practice, in terms of a similarity relation between possible worlds.
} 
control which does not undermine individual control. Such a notion is thought to be needed because responsibility-allocation was not meant to be a zero-sum game. Robust collective responsibility is supposed to be something more and other than individual responsibility, not a replacement for individual responsibility. As noted, this desideratum is only made more pressing by the fact that control exercised by people acting on behalf of collectives seems often to be uncompromised and undiminished.

Accordingly, an additional problem for the responsibility-collectivist is whether a causal understanding of group-control can be made consistent with this approach to robust collective responsibility. This, I will argue in this section, is doubtful. The reason is that none of the available solutions to the problem of "too many causes" is amicable to responsibility-collectivism, not at least as the position was originally conceived.

There are two ways in which supervenient and subvenient properties could be thought to be related in terms of causal influence. ${ }^{26}$ Either one excludes the other. This can happen through downward or upward exclusion. In the case of downward exclusion, the efficacy of the higher-level property entails denying causal efficacy to the lower-level property. In the case of upward exclusion, the opposite process takes place. Alternatively, it is also possible that there is no competition. Supervenient and subvenient properties may both be deemed to be causes of the same effect. ${ }^{27}$ Neither of these options is satisfactory for the responsibility-collectivist. Or so I will argue.

I begin with "exclusion scenarios". Since we are concerned with the question whether properties of collectives, that is, higher-level properties, can be causally efficacious, we can set aside the issue of upward exclusion here. In the case of downward exclusion, the causal efficacy of higher-level properties excludes the causal efficacy of lower-level properties despite the supervenience of the former on the latter. In Lawrence Shapiro's graphic formulation (2012, 53): "With downwards exclusion, the second-order [i.e., higher-order] property reaches down to snatch all the causal efficacy from its realizer."

The reason is the multiple realizability of higher-order properties. Given multiple realizability, counterfactuals linking the higher-level supervenient property $\left(\mathrm{P}_{\mathrm{H}}\right)$ to the relevant effect $\left(\mathrm{E}_{\mathrm{H}}\right)$ are both true $\left(\mathrm{P}_{\mathrm{H}} \square \mathrm{E}_{\mathrm{H}},-\mathrm{P}_{\mathrm{H}} \square \rightarrow-\mathrm{E}_{\mathrm{H}}\right){ }^{28}$ while the negative counterfactual (- $\mathrm{P}_{\mathrm{L}} \rightarrow-\mathrm{E}_{\mathrm{L}}$ ) linking the lower-lever subvenient property ($\left.P_{L}\right)$ to the same effect $\left(E_{L}\right)$ will be false (List \& Menzies 2009). ${ }^{29}$ This is because,

\footnotetext{
26 Many have argued that the exclusion principle should not be treated as an a priori claim (see esp. List \& Menzies 2009), and that whether exclusion holds or not is to be determined by empirical characteristics of the relevant systems.

27 But not because they overdetermine the effect. Overdetermination presupposes fully independent property instantiations or events as causes. The underlying rationale of the "non-competition scenario", as we will see shortly, is that supervenient properties are not wholly distinct from their realizers.

28 Whereby $\mathrm{P}_{\mathrm{H}}$ and $\mathrm{E}_{\mathrm{H}}$ are propositions referring to the instantiations of higher-level properties, while $\mathrm{P}_{\mathrm{L}}$ and $E_{\mathrm{L}}$ are propositions referring to the instantiations of lower-level properties.

29 Diverging from this approach, Woodward (2008) and Shapiro \& Sober (2012) argue that even in cases of multiple realizability causal claims involving subvenient lower-level properties need not be false or even less informative.
} 
given multiple realizability, it will not be true that the effect would not have happened without the lower-level property since multiple realizability entails that other lowerlevel properties could have realized the higher-level property. "We think of a cause as something that makes a difference, and the difference it makes must be a difference from what would have happened without it." - says Lewis $(1973,557)$. The point is that due to multiple realizability causal claims about the lower-level property do not satisfy the second part of the conjunct put forward by Lewis. This is because the same effect would have happened without the lower-level property. The absence of the lower-level property does not make a difference when the higher-level property is multiply realizable. Therefore, the higher-level property but not its lower-level realizing property will be causally efficacious.

For example, it is true (other things being equal) that the glass would not have cracked if the water had not boiled, and also that it did crack when the water did boil. But there is a huge number of possible micro states which can realize the relevant value for the temperature of the liquid. So it is not true that had a certain molecular arrangement not broken the glass, the glass would not have cracked. The counterfactual approach entails that the macroscopic, higher-level property is the cause of the cracking, not the microscopic property of a given micro-state of the molecules.

The same reasoning can be applied to collectives. There are many different ways to put together a mob capable and willing to destroy the Bastille. It is very unlikely that the relevant outcome, i.e., the destruction of the Bastille, would be dependent on the exact constitution of the mob. Again, the counterfactual approach implies that the mob qua mob was the cause of the Bastille's downfall, and not the properties of individuals which happened to constitute the mob on the given occasion. By the same token, it is highly probable that we will find a robust counterfactual correlation between higher-level property such as the interest rate set by the National Bank's and the relevant outcome such as the level of inflation. That is, "the effect would continue to occur across changes in the lower-level realization of its putative higher-level cause" (List \& Spiekermann 2012, 17). If so, then the counterfactual account suggests that the setting of the interest rate by the National Bank is the cause of changes in inflation, not the properties of individuals which realize the setting of the interest rate on the given occasion.

I will not question here the argument from multiple realizability to downward exclusion. Rather, the point I want to make here is that if higher-level and lower-level properties are related to one another as in the above scenario of downward exclusion, this will not help the responsibility-collectivist. If the causal efficacy of supervenient properties presupposes the exclusion of subvenient properties, then it would follow that attributing causal efficacy to the collective comes at the expense of denying causal efficacy to individual members of the collective. In short, whenever the collective is a causally efficacious factor, the individual members of the collective cannot be. And since the absence of causal efficacy entails the absence of causal control, it would also follow that causal group-control excludes individual control. Whenever the group is in control in the sense of being causally efficacious, the individual controlled by the collective does not exercise causal control.

The crucial issue is that this understanding is at odds with the responsibilitycollectivist's original desideratum of finding a notion of group-control which 
preserves individual control. If causal control is indeed necessary for moral responsibility, this understanding also entails that whenever the group is collectively responsible for some outcome, individual members are not individually responsible for the same outcome. This is because in such cases the causal efficacy attributed to the group regarding that outcome excludes the causal efficacy of individual members regarding the same outcome. ${ }^{30}$ Therefore, contrary to the original intentions of the responsibility-collectivists, what happens is not that collective responsibility will be something over and above the individual responsibility of group-members. Rather, responsibility will shift upwards from the individual level to that of the collective.

This implication, I believe, should seriously worry the responsibilitycollectivist. All the more so, if it is true, as is frequently claimed (see, for example, Kincaid 1986; Zahle 2003; List \& Menzies 2010), that most collective (and social) properties are indeed multiply realizable. The final point I want to make, however, is that the situation is even less encouraging for the responsibility-collectivist when higher-order and lower-order properties are not in competition for causal efficacy.

Higher-level and lower-level properties need not compete with one another. I now turn to this "non-competition scenario". The counterfactual account allows for the possibility that both a higher-level property and a lower-level property are causes of the same effect. This is the case when both the negative and positive counterfactuals are true for the higher-level property as well as for the lower-property realizing it $\left(\mathrm{P}_{\mathrm{H}} \square \mathrm{E}_{\mathrm{H}},-\mathrm{P}_{\mathrm{H}} \square \rightarrow-\mathrm{E}_{\mathrm{H}}, \mathrm{P}_{\mathrm{L}} \square \mathrm{E}_{\mathrm{L}},-\mathrm{P}_{\mathrm{L}} \square \rightarrow-\mathrm{E}_{\mathrm{L}}\right)$. This will clearly be the case when the relevant properties are identical.

Perhaps the higher-level property and the lower-level need not be identical for the same counterfactuals to apply to both of them with regard to some effect. However, and this is the crucial point here, if the same counterfactuals do apply to them with regard to some effect, then it is entailed by the counterfactual account that the higher-level property will have no causal powers or causal role over and above the causal powers or role of the lower-level property. This need not mean that the higherlevel property is epiphenomenal, but it does mean that the causal powers or role of the higher-level property is reducible to the causal powers or role of the lower-level property. $^{31}$

It should now be clear why the "non-competition scenario" is also unhelpful for the responsibility-collectivist. If the causal powers or causal role of higher-level properties are nothing over and above the causal powers or causal role of the lowerlevel properties realizing them, then the causal significance of collective properties too will reduce to the causal significance of the properties of individuals constituting the collective. If that is the case, however, then the collective will have no causal powers and will not play a causal role irreducible to the causal powers or causal role of its individual members. But that entails in turn that collectives cannot be said to exercise causal control. In fact, they cannot even be said to make a causal contribution

\footnotetext{
30 In addition, Pettit (1996) and List \& Pettit (2008) also worry that without individual control it is unlikely that the collective can display rational patterns of behaviour.

31 This is also admitted by those who think that multiple realizability entails downward exclusion. See, for example, List \& Spiekermann $(2012,17)$ : “[...] realization-sensitive causal relations are fully reducible to a lower level of description".
} 
over and above the causal contributions of their members. And so, in the "noncompetition scenario" there will be no basis for attributing moral responsibility to collectives over and above the moral responsibility of their individual members.

\section{8 "In conclusion, some ontology" ${ }^{\prime 2}$}

I summarize the above argument as the responsibility-collectivist's dilemma. Noncausal group-control does not undermine individual control, but it does not suffice for robust collective responsibility. Causal group-control can suffice for robust collective responsibility (provided other necessary conditions of "responsibility-fitness" have been met), but only in the "exclusion scenario" in which case causal group-control undermines individual control and hence individual responsibility. I have argued that this is bad news for the responsibility-collectivist.

Clearly, some important questions had to be postponed. I have not argued directly that causal control is necessary for moral responsibility. The failure of the "programming account" does provide support for that general claim. As noted, it is also a claim that is intuitively plausible and accepted by most authors on the subject. But not by everyone (see Kutz 2000; Sartorio 2004; Lawson 2012). It remains to be investigated how feasible these challenges to the requirement of causal control really are (for some doubts, see Petersson 2013). This is work for another day.

Instead, in closing I would like to ask about the implications of the conclusions drawn here for the individualism/holism debate. Any lessons learnt with regard to the problem of whether social wholes are something over and above their parts?

We have already noted that ontological individualism, i.e., the property supervenience thesis, is a widely accepted position. It is also assumed by responsibility-collectivists discussed in this paper. However, there are further dimensions of the individualism/holism debate. Pettit and Schweikard highlight three especially significant aspects (using a slightly idiosyncratic terminology, see esp. Pettit \& Schweikard 2006). The individualism issue, on Pettit's and Schweikard's understanding, concerns "the question of whether our individual intentional psychologies are compromised in any way by social regularities" (Pettit \& Schweikard 2006, 35; see also Pettit 1996). If individualism in this sense was false, then we would be "predetermined or predestined, notwithstanding our apparent intentional powers, to behave so that the regularities are sustained" (35). The atomism issue concerns "the question of whether there are any aspects of our individual intentional psychology such that we depend noncausally on having certain relations with one another for instantiating those features" (35-6). Finally, the singularism issue concerns the question of whether there can be group agents in the sense of being "centers of intentional attitude and action over and beyond singular agents" (36).

Clearly, it is the first issue of individualism (in terms of the definition in the previous paragraph ${ }^{33}$ ) and the third issue of singularism which the conclusions of this

\footnotetext{
32 I am importing here a section title from Pettit \& Schweikard (2006).

33 The position Pettit and Schweikard call individualism is to be distinguished from responsibilityindividualism. The latter view says that only individuals can be the addressees of ascription of responsibility. It is thus opposed to responsibility-collectivism. This section explores the relationship between individualism in Pettit's and Schweikard's sense and responsibility-individualism.
} 
paper bear upon. The connection to the third issue is obvious and undisputed by parties to the debate. Responsibility-collectivism presupposes anti-singularism. However, my final point to be made here is that responsibility-collectivism appears to be in tension with individualism. And since responsibility-collectivism presupposes anti-singularism, individualism and anti-singularism also conflict (pace Pettit \& Schweikard 2006).

Again, the conclusions of this paper do not necessarily clash with the claim that it is possible to ascribe autonomous mental states or attitudes to collectives, i.e., that collectives may have "minds of their own" (Pettit 2003). However, we find that the conditions for responsibility-collectivism are more demanding than its advocates may have previously thought. Specifically, we have seen that collectives can be causally efficacious qua collectives only by excluding the causal efficacy of individual contributions. Now, if we combine this conclusion with the "collective mind" hypothesis, we obtain the following. Whenever the collective is a causally efficacious "center of intentional attitude and action" with regard to some outcome, individuals constituting the collective will not be able to control that outcome via their intentional attitudes.

And thus, finally, we are in a position to recognize a more general implication, namely that the price of anti-singularism too may be higher than previously thought. This is because it begins to appear questionable whether anti-singularism really is consistent with individualism in Pettit's sense. If causally efficacious collective agency necessarily compromises individual control in the way described above, then it is hard to see how there can be group agents "distinct in an absolutely clear sense from their own members" (Pettit \& Schweikard 2006, 34-5), while at the same time the individuals constituting those group agents retain full control over their actions on behalf of the collective.

One way to understand the argument of this paper then is that it diagnoses a tension between individualism and anti-singularism - at least in cases in which the relevant "social regularities" depend on the reality of collective agents. If group agency undercuts the intentional powers of individuals as I have argued, then the price of anti-singularism may well be the denial of individualism. Since the arguments in favour individualism (persuasively set out in Pettit 1996, among others) appear to be strong, this speaks against anti-singularism in my view. But that polemic is work for another day. 


\section{REFERENCES}

Braham, M., \& van Hees, M. (2011). Responsibility voids. Philosophical Quarterly, 61, 615 .

Copp, D. (2006). On the agency of certain collective entities: An argument from normative autonomy. Midwest Studies in Philosophy, XXX, 194-221.

Crane, T. (2008). Causation, and determinable properties: On the efficacy of colour, shape and size. In J. Hohwy \& J. Kallestrup (Eds.), Being reduced. New essays on reduction, explanation, and causation (pp. 176-195). Oxford: Oxford University Press.

Epstein, B. (2009). Ontological individualism reconsidered. Synthese, 166, 187-213.

Fischer, J. M., \& Ravizza, M. (1998). Responsibility and control. A theory of moral responsibility. Cambridge: Cambridge University Press.

French, P. (1979). The corporation as a moral person. American Philosophical Quarterly, 16, 207-215.

French, P. (1984). Collective and corporate responsibility. New York: Columbia University Press.

Gilbert, M. (2002). Collective wrongdoing: Moral and legal responses. Social Theory and Practice, 28, 167-187. 635

Goetz, S. C. (1988). A noncausal theory of agency. Philosophy and Phenomenological Research, 49, 303-316.

Haji, I. (2006). On the ultimate responsibility of collectives. Midwest Studies in Philosophy, $X X X, 292-308$.

Held, V. (1970). Can a random collection of individuals be morally responsible? In L. May \& S. Hoffman (Eds.), Collective responsibility (pp. 89-100). Lanham: Rowman and Littlefield.

Jackson, F., \& Pettit, P. (1990). Program explanation: A general perspective. Analysis, 50, $107-117$.

Jackson, F., \& Pettit, P. (1992a). In defense of explanatory ecumenism. Economics and Philosophy, 8, 1-21. 645

Jackson, F., \& Pettit, P. (1992b). Structural explanation in social theory. In D. Charles \& K. Lennon (Eds.), Reduction, explanation, and realism (pp. 97-132). Oxford: Clarendon.

Kincaid, H. (1986). Reduction, explanation, and individualism. Philosophy of Science, 53, 492-513.

Kutz, C. (2000). Complicity. Cambridge: Cambridge University Press.

Lawson, B. (2012). Individual complicity in collective wrongdoing. Ethical Theory and Moral Practice, 16, 227-243.

Lewis, D. (1973). Causation (Philosophical papers, Vol. II, pp. 159-171). New York: Oxford University Press.

List, C. (2006). The discursive dilemma and public reason. Ethics, 116, 362-402.

List, C., \& Menzies, P. (2009). Non-reductive physicalism and the limits of the exclusion principle. Journal of Philosophy, 106, 475-502.

List, C., \& Menzies, P. (2010). The causal autonomy of the special sciences. In C. Macdonald \& G. Macdonald (Eds.), Emergence in mind (pp. 108-128). Oxford: Oxford University Press. 
List, C., \& Pettit, P. (2002). The aggregation of sets of judgments: An impossibility result. Economics and Philosophy, 18, 89-110.

List, C., \& Pettit, P. (2008). Group agency and supervenience. In J. Hohwy \& J. Kallestrup (Eds.), Being reduced. New essays on reduction, explanation, and causation (pp. 75-92). Oxford: Oxford University Press.

List, C., \& Pettit, P. (2011). Group agency: The possibility, design, and status of corporate agents. Oxford: Oxford University Press.

List, C., \& Spiekermann, K. (2012). Methodological individualism and holism in political science: A reconciliation (Unpublished Working Paper). http://personal.lse.ac.uk/list/

May, L. (1991). Metaphysical guilt and moral taint. In M. Larry \& H. Stacey (Eds.), Collective responsibility (pp. 239-254). Lanham: Rowman and Littlefield.

May, L., \& Hoffman, S. (Eds.). (1991). Collective responsibility. Lanham: Rowman and Littlefield.

McKenna, M. (2006). Collective responsibility and an agent meaning theory. Midwest Studies in Philosophy, XXX, 16-34.

Menzies, P. (2008). The exclusion problem, the determination relation, and contrastive causation. In J. Hohwy \& J. Kallestrup (Eds.), Being reduced. New essays on reduction, explanation, and causation (pp. 196-218). Oxford: Oxford University Press.

Miller, S., \& Mäkelä, P. (2005). The collectivist approach to collective moral responsibility. Metaphilosophy, 36, 634-651.

Moore, S. M. (2009). Causation and responsibility: An essay in law, morals, and metaphysics. Oxford: Oxford University Press.

O’Connor, T. (1994). Emergent properties. American Philosophical Quarterly, 31, 91-104.

O'Connor, T. (1995). Agent causation. In T. O'Connor (Ed.), Agents, causes, and events: Essays on indeterminism and free will (pp. 173-200). Oxford: Oxford University Press.

Petersson, B. (2013). Co-responsibility and Causal Involvement. Philosophia, 41, 847-866.

Pettit, P. (1996 [1993]). The collective mind. New York: Oxford University Press.

Pettit, P. (2003). Groups with minds of their own. In F. Schmitt (Ed.), Socializing metaphysics (pp. 167-193). New York: Rowman and Littlefield.

Pettit, P. (2007a). Responsibility incorporated. Ethics, 117, 171-201.

Pettit, P. (2007b). Rationality, reasoning and group agency. Dialectica, 61, 495-519.

Pettit, P., \& Schweikard, D. (2006). Joint actions and group agents. Philosophy of the Social Sciences, 36, 18-39.

Sartorio, C. (2004). How to be responsible for something without causing it. Philosophical Perspectives, 18, 315-336.

Shapiro, L. A. (2000). Multiple realizations. Journal of Philosophy, 97, 635-654.

Shapiro, L. A. (2012). Mental manipulations and the problem of causal exclusion. Australasian Journal of Philosophy, 90, 507-524.

Shapiro, L. A., \& Sober, E. (2012). Against proportionality. Analysis, 72, 89-93.

Shockley, K. (2007). Programming collective control. Journal of Social Philosophy, 38, 442 455.

Szigeti, A. (2014). Are individualist accounts of collective responsibility morally deficient? In A. Konzelmann-Ziv and Hans Bernhard Schmid (Eds.), Institutions, Emotions, and Group Agents. Contributions to Social Ontology (pp. 329-342). Dordrecht: Springer. 
Woodward, J. (2003). Making things happen: A theory of causal explanation. New York: Oxford University Press.

Woodward, J. (2007). Causation with a human face. In H. Price \& R. Corry (Eds.), Causation, physics, and the constitution of reality (pp. 66-105). Oxford: Oxford University Press.

Woodward, J. (2008). Mental causation and neural mechanisms. In J. Hohwy \& J. Kallestrup (Eds.), Being reduced. New essays on reduction, explanation, and causation (pp. 218262). Oxford: Oxford University Press.

Yablo, S. (1992). Mental causation. Philosophical Review, 101, 245-280.

Ylikoski, P. (2012). Micro, macro, and mechanisms. In H. Kincaid (Ed.), The Oxford handbook of philosophy of social science (pp. 21-45). Oxford: Oxford University Press.

Zahle, J. (2003). The individualism-holism debate on intertheoretic reduction and the argument from multiple realization. Philosophy of the Social Sciences, 33, 77-99.

Zahle, J. (2007). Holism and supervenience. In S. P. Turner \& M. W. Risjord (Eds.), Handbook of the philosophy of science (pp. 311-341). New York: Elsevier. 